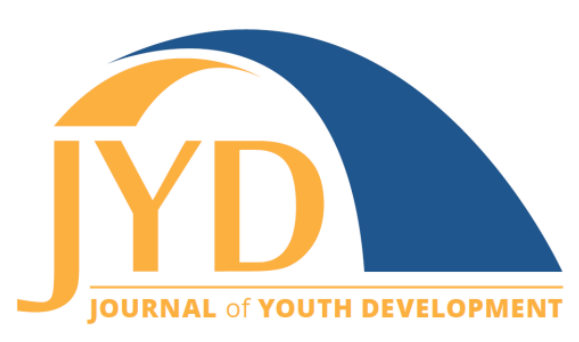

http://jyd.pitt.edu/ | Vol. 15 Issue 6 DOI 10.5195/jyd.2020.800 | ISSN 2325-4017 (online)

\title{
Exploring the Impacts of State 4-H Council Service on Career Readiness
}

\author{
Bradd LeBow Anderson \\ 4-H Center for Youth Development, University of Missouri \\ andersonb@missouri.edu
}

\begin{abstract}
The State 4-H Council of Missouri 4-H is an experiential leadership opportunity that engages youth as valued, contributing partners and ambassadors of the 4-H organization. While several state programs have a state 4-H council, there is little research regarding these councils or the impacts of state 4-H council service. This study employed a hermeneutic phenomenological approach to explore the experience of State 4-H Council service among alumni within a framework of positive youth development theory. Council membership was found to carry expectations for lasting relationships and a sense of connectedness. In the area of leadership, State 4-H Council service was found to enhance understanding, develop strategies, and foster specific skills that allowed members to utilize these abilities in the early stages of their careers.
\end{abstract}

Key words: state 4-H council, positive youth development, career readiness, leadership, phenomenology

Prepared leaders can wield critical influence in the rise of cultures, the growth of human opportunity, and the lasting direction of world events. State 4- $\mathrm{H}$ councils are a traditional part of many state 4- $\mathrm{H}$ programs, and membership on such a council is commonly considered the pinnacle of a 4-H career (Bruce, 2003). Youth in these groups are commonly viewed as ambassadors of $4-\mathrm{H}$, role models to other youth, and representatives of the voice of youth to the state 4-H program. This interpretative phenomenological study explored the lasting impacts of service on Missouri's State 4-H Council on college and career readiness in young adulthood. For the purposes of this article, the term State $4-H$ Council will be capitalized only when referring specifically to the Missouri body.

(cc) EY New articles in this journal are licensed under a Creative Commons Attribution 4.0 License. This journal is published by the University Library System, University of Pittsburgh and is cosponsored by the University of Pittsburgh Press. The Journal of Youth Development is the official peer-reviewed publication of the National Association of Extension 4-H Youth Development Professionals and the National AfterSchool Association. 


\section{Previous Related Studies}

While the body of scholarly literature on the 4-H experience is growing, there is a large gap in the research regarding service on a state 4-H council (Bruce, 2003; Leech, 2007) and only four published studies (Boleman et al., 2008; Bruce et al., 2004, 2005; Kelsey, 2020) have examined this experience specifically. Together, these studies suggest that serving on a state 4-H council can be valuable to the development of youth and provide insights into particular areas of development. Common themes include career readiness, leadership development, and the building of close relationships with other council members.

A phenomenological approach enabled this study to examine these themes in further detail, through the context of a state 4-H council that aligns with many of the operational recommendations made by Bruce et al. (2004). One example is the opportunity to make impactful decisions, as Missouri's State 4-H Council members are responsible for leadership roles in planning two premiere state $4-\mathrm{H}$ events. The first is Teen Conference, a leadership development experience designed to foster belonging, independence, mastery, and generosity in youth ages 11 to 13 . The other event is State 4-H Congress, a college and career readiness experience for youth ages 14 to 18 , that also includes campaigns and elections for the next State 4-H Council.

\section{Methods}

The sample for this study was comprised of 15 individuals who had served on Missouri's State 4-H Council during the 2011-2013 timeframe. Due to the highly contextualized conditions of this study, all were invited to participate through personal outreach in a purposive sampling technique and data collection took place through individual semi-structured interviews. Members were in their mid-20s with communities of origin that ranged from rural Missouri, small towns, metropolitan suburbs, and large cities. At the time of the study, six members of the sample were students exclusively, six were working full time in their chosen career, and three were engaged in their career while taking university classes to complete their master's degrees. Seven members of the sample were male and eight were female. One male and one female member of the sample are Black and 13 are White.

This study was conducted through the perspective of a research practitioner, through my role as the coordinator of Missouri's State 4-H Council during the period of study. As G. Anderson and Herr (1999) note, the validity of practitioner research is often viewed with skepticism by 
portions of an academic community wary of the "personal stake and substantial emotional investment" (p. 13) of the practitioner in their own projects. However, as Lincoln and Guba (1985) point out, the prolonged engagement and persistent attention over time of a research practitioner offers a potential for a meaningful scope and depth to a study of this topic that might otherwise be unattainable.

This study was conducted through a hermeneutic phenomenological approach. Phenomenology is particularly well-suited for exploring and interpreting highly contextualized experiences (Rossman \& Rallis, 2016), and Heidegger's hermeneutic approach utilizes the lived experiences of the research practitioner as an asset to enrich the data by providing frames of meaning into the experiences being studied during the data gathering process (Bradbury-Jones et al., 2009). To account for my biases, I engaged in standard qualitative practices which compel the phenomenological researcher to further clarify their interviews and settings (Groenewald, 2004), including reflective memos and written field notes.

\section{Results}

Analysis of the data resulted in three themes directly related to relationships, leadership, and career preparation. Together, these data describe impacts of State 4-H Council service that the sample viewed as highly important to their success after high school. Pseudonyms are used for all sample members in the results presented below.

\section{Relationships}

Several members of the sample described their State 4-H Council experience as taking place within a family-like atmosphere and expressed feelings of closeness to other Council alumni even though they were not in regular communication. Ridley shared:

If I needed them to be there or I needed a favor or if I wanted to say something to them, I felt like I could pick up the phone and call anyone. There isn't a moment in my mind where they wouldn't pick up the phone. I think that's because it truly was like a family environment.

Most expected that any need for mutual support from their fellow Council alumni would be met if the need were to arise, and all had left the State 4-H Council experience with this expectation in place. At one extreme of this range were Brock and Rebeccah, who met on State 4-H Council and were 2 weeks from their wedding at the time of data collection. At the other end of this 
range was Annabeth, who did not feel that her Council relationships had followed her in life, despite her previous expectations to the contrary. Annabeth elaborated on the disconnect between her expectations of these relationships and her reality:

It was like, "Oh my gosh, you will make so many"-emphasizing SO MANY— "lifelong friends." The truth? ONE. Not because they don't care about me, but because they're doing their own thing. You were with some of those people for like 3 years, and they got married and you weren't even invited, you know? I'm pretty sure Ridley's in D.C. and I don't even think we even "Happy Birthday" each other anymore. And it's not that you don't matter and it's not the relationship that you have with them didn't matter . . . not because they don't care about you, not because you didn't honor or respect the relationship you had. It's just that you've grown apart.

While none of the sample were still in contact with large numbers of their council peers, almost all shared a perception that their State 4-H Council experience resulted in lasting networks and described encounters with fellow alumni at events and through shared associations. Carrie shared:

I would have never thought while I was on Council, the people I met, how they would just continue to be in my life. And not just through work. The other day I met somebody kind of in passing who is a police officer from Ellerton. I was like, "Oh, my friend Jackson is a police officer, a highway patrolman in Ellerton!" And he said, "Oh yeah, he's my favorite highway guy! Every time I pull up on a scene and I know he's gonna be there, I know it's gonna be a good day."

\section{Leadership Development}

Sample members described developing a view of themself as a leader through their State 4-H Council experience. However, beyond the perceptions of themselves as leaders, the development of specific leadership abilities was also a strong theme among all members of the sample. They explored this theme in terms of learning to organize others, finding their own leadership voice, developing leadership strategies, and gaining experience from making impactful decisions. For Billie, a photojournalist now working with the New York Times, the ability to organize other people is a critical skill developed through her State 4-H Council experience.

Council taught me that if you want anything to happen, you have to get enough people to buy into it, to really want to be a part of it too, and to see that vision 
Impacts of 4-H Council Service on Career Readiness

that you're creating. I think we practiced that over and over again when we would plan events or even when we wanted to make a change that we saw within our own region or at the state level.

\section{Understanding Leadership}

Through actual experience, members grew beyond their preconceptions of leadership and formed experience-based understandings, as Brock explained:

Going in, the idea [of] what I thought was a good leader might have been micromanagement . . . [but] each situation demands a different type of leadership. Some people like to be told each and every move, and other people like to be given a broad idea and like to use their own creativity and go from there. People come to you saying, "I got this problem," and mostly people just want to be heard. There's not even a real solution and they don't need a real solution a lot of times. They need to be heard, and voicing that to you is really what they need."

\section{Finding a Leadership Style.}

Members of the sample described the process of joining the Council, ascertaining the wide range of leadership styles, and finding their place in a group that was densely packed with strong leaders. "I think naturally a lot of people were kind of wanting to be like the main leadership position, like take charge of this and take charge of that," recalled Masoud. For Taraji, being one of the leaders was important. "I know most of the time I was pretty much able to speak my mind if I had ideas, and sometimes people would kind of roll with it or they kind of like switched it around a little bit, but I was always able to speak to my mind."

Others found value in learning to pick one's battles. "Sometimes you have to decide what hill you're going to die on," said Johnny. "For me, the Congress t-shirts were not the one." Others still were content to leave the top leadership roles to those who desired them most. "I don't think I was like a leader on council," said Rebeccah. "I think I was more of a follower on Council, because there's so many people that, like, had a lot of passion and like they wanted to be like the main leader. But then in my community I was more of a leader."

\section{Developing Leadership Strategies}

Through their work with different age groups at Teen Conference and State 4-H Congress, these Council members realized a need to develop alternate leadership strategies. Some found greater meaning in Teen Conference, the event for younger youth in which they played more 
extensive roles. Others drew more value from leading their peers at State 4- $\mathrm{H}$ Congress, as Carrie described:

As a professional you are a lot of times the same age as your workers, or even younger, and so you have to know how to get along with them and be friendly with them, but "don't cross that line" because you are in a leadership role. So, I thought State 4-H Congress definitely taught us that, which is awesome.

\section{Developing Leadership by Committee}

The daunting challenge of planning two large events was made possible by breaking responsibilities down into manageable tasks. This process created opportunities for skill development and made the process more manageable for the adult professionals in charge (Henness \& Ball, 2019). Through committee work, the State 4-H Council members learned about themselves as leaders and began to develop more effective leadership strategies. "On your committee you had to really take off and go with it," said Mary. "Making sure everyone on our committee was working through their part of it to make sure that everything was where it needed to be was very important." For Grace, the committee experience was more meaningful than even the officer role she later served in. "I was the chair of that (committee) one year and that was my favorite leadership opportunity I had," she said. Brock shared that committee work was important to building strong relationships on Council, noting "I think we got quite a bit of work done, but I think during those individual times we probably also learned the most about people."

The sample reported that the focus of Missouri's State 4-H Council on committee work provided them opportunities to make impactful decisions, develop relationships, and learn about themselves in the course of their duties. By developing the skills to organize others, finding their own leadership voice, developing individual leadership strategies, and experiencing involvement in making impactful decisions, these data from the college-aged members of this sample offer specific and measurable avenues of research on 4-H impacts in this demographic.

\section{Career Preparation}

All members of the sample were currently on career or academic paths that satisfied them, and they described State 4-H Council experience as a key influence in their career readiness after high school. The subthemes that arose from the sample included inspiration and direction, the ability to motivate others, experience with diversity, the capacity to adapt, and experience working in teams. 


\section{Inspiration and Direction}

As members progressed through high school, the individual-context relationship of the State 4-H Council experience included working with older youth who were on positive life trajectories of their own. This exposure influenced younger members, who often did not encounter pushes towards higher education in their communities of context. Members shared that this opened new possibilities that some may not have previously considered attainable, provided a developmental roadmap, and helped younger members ready themselves more quickly for the next steps after high school. "Coming in being 16 and I see these 18, 19, 20 year-olds doing college, and like what they have to do to succeed, it gets you ready," said Annabeth. "It gets you ready faster."

\section{The Ability to Motivate Others}

As the sample progressed through the early stages of their career path, the role of motivational abilities emerged as a key to preparedness and success. The ability to motivate others effectively in the absence of authority or capital, which a more seasoned professional might enjoy, served as a valued asset to their early career success. This allowed them to utilize their skill sets in the absence of power or control, as Johnny explained:

While I don't necessarily have authority over certain individuals, I very much so have some responsibility for them doing what they're supposed to be doing. . . . There's people that aren't going to agree with you and are going to do their own thing, but it kind of helps you to prep and navigate how you can manage those sorts of things. Maybe you need to have a one-on-one discussion with someone or maybe they're just struggling and need help. That's one thing that's really helped me a lot. Being able to get people to do what needs to be done, even when you're not the one that signs their paycheck, is pretty valuable.

\section{Experience With Diversity}

The experiential progression of working alongside diverse others had long lasting career impacts for members of the sample. One example is Jackson, now a law enforcement officer, who had little experience with diversity in his community of origin that would prepare him for pursuit of his career goals in the outside world. Reflecting on his State 4-H Council experience, Jackson stated:

You know, I apply things that I learned as a Council member. As a Council member, you get to work with people from all across the state, all ethnic backgrounds, and . . you're going to meet people that have different religions 
and different foods and have a different way of thinking. I think it has definitely helped me in my career goals in understanding and accepting people. I think it enhanced (my ability) to be more open to people's thoughts and beliefs and to not look down on people. "You do you," and if it's not affecting me or someone else, I don't care. As long as you're not causing havoc, I'm not worried about it.

\section{Experience Working in Teams}

Through their work on committees and in small groups, members shared that their experience with interpersonal dynamics helped them develop leadership abilities in smaller group settings. This was exemplified by Randal, who was promoted in the last year to a new role in the field of advanced generators, leading a PowerGen team in Chicago that repairs priority generators at hospitals and other critical locations. Reflecting on his Council experience in his ability to lead a newly forming team, Randal shared:

I'm seeing a lot of familiar, familiar things happening. You have to take all these different ages and these different personalities and you're with [them] . . 9, 10 hours a day sometimes. I'm enjoying it more because of that group [State 4-H Council]. I've definitely taken on pretty much the same role in this group that I [had] within Council, except a lot more serious.

\section{Discussion}

Reflecting their stage of life, this sample indicated that at the present time their most important goals are career-focused. Leadership emerged as a primary focal point in the interviews, as sample members recounted that unique opportunities afforded by Council membership catalyzed a growth in their abilities to pursue these goals successfully. The processes of planning the Teen Conference and State 4-H Congress events were accomplished by breaking component tasks into small committees. Through this committee work, the sample reported forming relationships, building networks, building an understanding of the nature of leadership, and developing effective leadership skills. These skills included abilities to motivate others, adapt leadership strategies to changing audiences, and identify a leadership approach within a group of other leaders.

Through the building of leadership skills, modeling of older youth, and acquisition of cultural competencies, the sample indicated that valuable career preparation occurred. The exposure to older youth on positive life trajectories influenced younger members in both leadership development and in the pursuit of higher learning after high school. Members of the sample 
stated that the diversity of State 4-H Council members and the mix of urban and rural cultures allowed them to have experiences with diversity that they would not otherwise have received during their adolescence. This, in combination with personal growth and leadership skills they developed through their Council experience, empowered the sample to pursue leadership positions in the organizations they became interested in, and utilize their leadership abilities even in the absence of power or authority. It also opened doors to occupational and academic aspirations that they felt they would have not previously considered to be within reach.

\section{Implications}

Youth development programs should engage teens in impactful decision-making opportunities based around individuals and contexts that they value. Teens should be treated as contributing partners with unique individual abilities and engaged in meaningful decisions that go far beyond t-shirt designs and event themes, as advocated by Henness and Ball (2019). Members and programs can both benefit when youth are expected-not just allowed-to make consequential decisions as valued partners in youth development. This creates meaningful work that spurs the formation of relationships, increases receptiveness to adult mentoring, and creates developmental opportunities that lay the groundwork for leadership and career readiness.

Youth-serving professionals should be aware that structural components of the process can lead to positive developmental outcomes, when purposefully designed to facilitate interaction and ideation. In this study, the formation of committees allowed the large responsibilities of program planning to be broken down into manageable tasks. This created opportunities for youth to build relationships, explore leadership, and be guided by adult mentors in ways that they were receptive to. Time-sensitive responsibilities embedded with a need for urgency and focus can offer youth of diverse racial, ethnic, and cultural backgrounds a means to engage with each other and work towards common goals. Experience in working with diverse peers brought important benefits for all in this study, as members who joined Council with limited multicultural experience transitioned into careers. The alumni in the sample credited experience with diversity as a major contributor to their career successes in young adulthood.

\section{Conclusion}

State 4-H Council service can provide unparalleled opportunities for youth to develop as leaders and prepare for future careers. J. Anderson et al. (2010) reported that many of the 4-H alumni in their study believed their general 4-H experience influenced their professional development. In their study of Texas State 4-H Council alumni, Boleman and colleagues (2008) found that 
$71.4 \%$ of their sample reported that the state $4-\mathrm{H}$ council experience specifically had an influence on their career goals. The present study offers further insight into ways that state 4-H council service can influence individual career success and adds insight as to why that may have been the case in the other studies as well.

This study identified specific components of leadership development that offer measurable avenues for further research on 4-H impacts in the largely understudied college-aged demographic. These include developing the skills to organize others, finding one's own leadership approach, developing individual leadership strategies, building relationships with diverse others, and providing experience in making impactful decisions. This study suggests that service on a state 4- $\mathrm{H}$ council may bring specific benefits, even beyond that of general $4-\mathrm{H}$ experience, to help youth position themselves for success as they move into young adulthood and pursue careers.

\section{References}

Anderson, G., \& Herr, K. (1999). The new paradigm wars: Is there room for rigorous practitioner knowledge in schools and universities? Educational Researcher, 28(5), 12-40. https://doi.org/10.3102/0013189X028005012

Anderson, J., Bruce, J., \& Mouton, L. (2010). 4-H made me a leader: A college-level alumni perspective of leadership life skill development. Journal of Leadership Education, 9(2), 35-49. https://doi.org/10.12806/V9/I2/RF3

Boleman, C. T., Merten, K., \& Hall, G. W. (2008). State 4-H council: A look back at what it meant to serve. Journal of Extension, 46(1). http://www.joe.org/joe/2008february/rb5.php

Bradbury-Jones, C., Sambrook, S., \& Irvine, F. (2009). The phenomenological focus group: An oxymoron? Journal of Advanced Nursing, 65(3), 663-671.

Bruce, J.A. (2003). The transfer of training and skills by Texas State 4-H Council members: $A$ qualitative study (Unpublished doctoral dissertation). Texas A\&M University, College Station.

Bruce, J. A., Boyd, B. L., \& Dooley, K. E. (2004). Leadership life skills demonstrated by state 4-H council members. Journal of Extension, 42(5), 1-7. https://www.joe.org/joe/2004october/a6.php

Bruce, J. A., Boyd, B. L., \& Dooley, K. E. (2005). Evaluation of transfer of training and skills learned as state 4-H council members. Journal of Leadership Education, 4(1), 52. https://doi.org/10.12806/V4/I1/RF1

Groenewald, T. (2004). A phenomenological research design illustrated. International Journal of Qualitative Methods, 3(1), 42-55. https://doi.org/10.1177/160940690400300104 
Journal of Youth Development | http://jyd.pitt.edu/ | Vol. 15 Issue 6 DOI 10.5195/jyd.2020.800

Impacts of 4-H Council Service on Career Readiness

Henness, S. A., \& Ball, A. (2019). Engaging youth as influencers in leadership event planning. Journal of Human Sciences and Extension, 71 , 144-154.

Kelsey, K. D. (2020). The sharpening stone: A phenomenological study of the impact of a 4-H state-level leadership role on youth leadership and life skills development. Journal of Human Sciences and Extension, 8(1), 1-16.

Leech, K. K. (2007). The relationship between emotional intelligence, character, and leadership traits in the members of the Texas 4-H Council (Doctoral dissertation). Texas Tech University, Lubbock.

Lincoln, Y.S., \& Guba, E.G. (1985). Naturalistic inquiry. Sage

Rossman, G. B., \& Rallis, S. F. (2016). An introduction to qualitative research: Learning in the field. Sage. 